\title{
EDUCAÇÃO EM SAÚDE E CIDADANIA: REVISÃO INTEGRATIVA
}

\author{
HEALTH EDUCATION AND CITIZENSHIP: INTEGRATIVE REVIEW
}

EDUCACIÓN EN SALUD Y CIUDADANÍA: REVISIÓN INTEGRADORA

\author{
Viviane Ferraz Ferreira ${ }^{1}$ \\ Genylton Odilon Rêgo da Rocha ${ }^{2}$ \\ Márcia Maria Bragança Lopes ${ }^{3}$ \\ Milena Silva dos Santos ${ }^{4}$ \\ Shirley Aviz de Miranda ${ }^{5}$
}

Resumo Este artigo apresenta os resultados de uma revisão integrativa de literatura sobre educação em saúde e cidadania, que buscou conhecer e analisar as diferentes contribuições científicas disponíveis. A educação em saúde reflete uma estratégia que almeja um cidadão coautor do processo de construção do cuidado à sua saúde. Utilizou-se para a coleta de dados a base Lilacs (Literatura Latino-Americana do Caribe em Ciências da Saúde) no período de 2000 a 2011, totalizando 79 produções. Após a aplicação dos critérios de inclusão e exclusão, a amostra final incluiu dez publicações. A pesquisa trouxe a prevalência de estudos da natureza artigo, apresentando mais de três autores, com predominância de docentes e produção do tipo revisão teórica. As categorias que emergiram do estudo foram: educação em saúde - historicidade e bases conceituais; e educação popular como geradora de cidadania. As evidências mostraram o processo histórico das políticas de saúde e o surgimento dos movimentos sociais voltados para as necessidades da população. Destacaram também que a educação permanente em saúde proporciona a construção de novos saberes, mediante a junção de conhecimentos científicos e de saberes populares. Manifestaram-se na literatura contribuições relevantes sobre a educação em saúde, por ser uma prática emancipadora do sujeito, atuando como espaço gerador de cidadania.

Palavras-chave educação em saúde; cidadania; educação.
Abstract This article presents the outcome of an integrative literature review on health education and citizenship that sought to understand and analyze the different scientific contributions available. Health education reflects a strategy that seeks a citizen who is a co-author of the process of building his or her own health care. The LILACS (Latin American and Caribbean Center Health Sciences Information) database was used to collect the data in the period ranging from 2000 to 2011, with a total of 79 publications. After applying the inclusion and exclusion criteria, the final sample consisted of ten articles. The study revealed the prevalence of article studies with more than three authors - predominantly professors -, and of theoretical reviews. The categories that emerged from the study were health education - historical background and conceptual foundations, and popular education as an engine for citizenship. The evidence showed the historical process of the health policies and the emergence of social movements targeting the needs of the population. They also highlighted that continuing health education allows for the construction of new knowledge by blending scientific and popular knowledge. The literature shows relevant contributions on health education, as it is an emancipatory practice of the subject acting as a space that generates citizenship.

Keywords health education; citizenship; education. 


\section{Introdução}

A educação em saúde (ES) é uma importante ferramenta no processo de conscientização individual e coletiva de responsabilidade e direitos à saúde. É um processo inerente a todas as práticas desenvolvidas no âmbito do Sistema Único de Saúde (SUS). Por ser uma prática transversal, proporciona a articulação entre todos os níveis de gestão do sistema, representando, desta maneira, um dispositivo essencial tanto para a formulação da política de saúde como para as ações que acontecem na relação direta dos serviços com os usuários (Brasil, 2007a).

A estratégia da ES visa integrar vários saberes científicos e do senso comum, permitindo aos envolvidos uma visão crítica, participativa e autônoma (Reis, 2006). Com isso, a prática de educação em saúde pode permitir o vínculo com ideias de reflexão crítica sobre realidade, empoderamento comunitário e transformação do status quo, na perspectiva de criação e ampliação das condições de vidas saudáveis (Lopes, 2009). Desta forma, possibilita a construção da cidadania, em razão da relação que é criada entre indivíduo e seu ambiente (Fernandes e Backes, 2010).

É sabido que cidadão é todo indivíduo que goza de direitos constitucionais e respeita as liberdades democráticas, cumprindo deveres que lhe são atribuídos como participante ativo da sociedade. Por meio da educação, desenvolvem-se indivíduos com consciência crítica para que possam ser criativos, livres e agentes transformadores da realidade e não simplesmente reprodutores de uma mentalidade equivocada. É somente por meio da educação que o indivíduo se desenvolve e se torna cidadão com autonomia (São Paulo, 2009).

Freire (2011b) enfatiza que a prática educativa deve ser realizada com alegria, esperança, convicção de que a mudança é possível, curiosidade, comprometimento, tomada de decisões e disponibilidade ao diálogo, sabendo escutar o outro e querendo bem ao educando (Freire, 2011b). Ainda para Freire (2011a), a educação deve ser uma prática da liberdade do ser humano, na qual os conhecimentos são compartilhados entre os sujeitos que desvelam a realidade, conhecem-na criticamente e a recriam.

Com base na concepção de que a educação em saúde é um campo que visa à promoção da saúde e à aproximação direta entre profissionais e usuários, na busca de uma relação que permita a coparticipação, a questão a seguir surge como norteadora da pesquisa: como a educação em saúde tem promovido caminhos basilares acerca do direcionamento da construção de uma cidadania que vise ao cidadão como coautor no processo de formação do cuidado à saúde?

É importante traçar os aspectos históricos e conceituais sobre a ES para se conhecerem informações relevantes em relação ao direcionamento que as práticas educativas em saúde estão tomando na construção de uma cida- 
dania - assim como entender as mudanças na sociedade, com a aproximação do mundo popular, agregando, no campo da saúde, propostas que permitam retomar o indivíduo como ser cidadão, participativo e consciente de sua condição de vida.

Com base nessas informações é que se justifica nosso interesse em promover uma revisão integrativa da literatura na área da educação em saúde, contribuindo para posteriores pesquisas sobre a temática. Portanto, busca-se com este trabalho conhecer as diferentes contribuições científicas disponíveis sobre o tema e analisar os resultados em evidência sobre educação em saúde e cidadania.

\section{Percurso metodológico}

Estudo de natureza bibliográfica, desenvolveu-se por meio de uma revisão integrativa da literatura, recurso este que proporciona a incorporação das evidências científicas para a prática dos profissionais que trabalham com a educação em saúde, tanto na pesquisa quanto na assistência.

A revisão integrativa da literatura é um método de revisão mais amplo, pois permite incluir literatura teórica e empírica, bem como estudos com diferentes abordagens metodológicas (quantitativa e qualitativa). Os estudos incluídos na revisão são analisados de forma sistemática em relação aos seus objetivos, materiais e métodos, permitindo que o leitor analise o conhecimento preexistente sobre o tema investigado (Pompeo, Rossi e Galvão, 2009).

Para melhor sistematização, seguiu-se a descrição das fases que compõem a revisão integrativa da literatura, segundo Souza, Silva e Carvalho (2010), as quais elucidam que, na primeira fase, deve-se elaborar uma pergunta norteadora; na segunda, buscar a amostragem na literatura; na terceira, iniciar a coleta de dados; na quarta, realizar a análise crítica dos estudos incluídos; na quinta, fazer a discussão dos resultados; e, por fim, na sexta fase, apresentar a revisão integrativa da literatura.

A busca dos estudos foi realizada na base de dados Literatura Latino-Americana e do Caribe em Ciências da Saúde (Lilacs). A escolha da base ocorreu em razão da amplitude no que tange à abrangência dos periódicos. Foram identificadas várias produções sobre o tema. A seleção do material para estudo foi realizada mediante os descritores 'Educação em saúde' e 'Cidadania', no período de 2000 a 2011. Os critérios de inclusão utilizados para a seleção da amostra foram: artigos completos, monografias e teses publicadas que abordassem a temática em questão. Os critérios de exclusão foram somente artigos incompletos, produções anteriores ao ano de 2000.

Inicialmente, selecionaram-se 79 produções científicas, publicadas entre 2000 e 2011 . A coleta de dados ocorreu durante o mês de janeiro de 2012, 
com base em um formulário preenchido para cada produção do estudo conforme o Quadro 1. Esse formulário permitiu a síntese dos dados, organizada em dois eixos, os quais possibilitaram a obtenção de informações sobre a caracterização das produções e os resultados em evidência.

\section{Quadro 1}

Formulário sobre o perfil das produções e os resultados em evidência, Belém-Pará

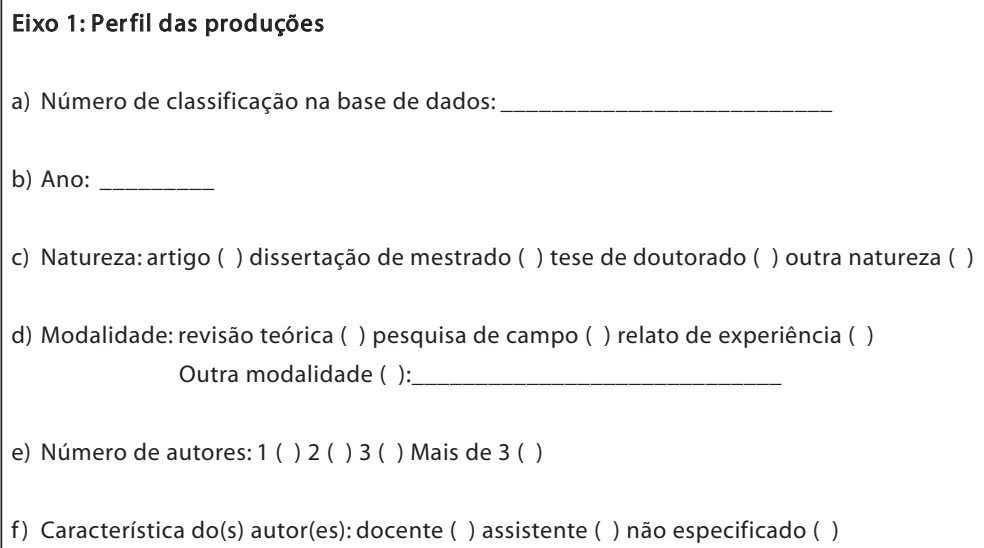

Fonte: Os autores.

Foi realizada a avaliação crítica dos artigos selecionados para verificar se respondiam plenamente à pergunta norteadora. Em seguida, analisaram-se todas as produções encontradas na base de dados, após a filtragem pelos critérios de inclusão e exclusão, e buscaram-se o rigor e as características de cada artigo.

Após a leitura dos textos, foi constatado que, das 79 produções, apenas dez estudos tinham afinidade com o tema e atendiam aos critérios de seleção. Numeraram-se os artigos conforme a ordem de localização. Os dados foram analisados de acordo com as abordagens temáticas 'educação em saúde' e 'cidadania'. Para apresentar os resultados, visualizados no Quadro 2, tomou-se por base cada um dos eixos identificados no formulário e foram produzidas duas categorias temáticas. 
Distribuição dos artigos incluídos na revisão integrativa da literatura, de acordo com título, autores, periódicos e ano de publicação

No

Título do artigo

1 Grupos de educação em saúde: aprendizagem permanente com pessoas soropositivas para o HIV.

2 Estratégias de enfrentamento dos dilemas bioéticos gerados pela violência na escola.

3 Educação popular em saúde com a comunidade indígena Xukuru do Ororubá-PE.

4 Democracia e participação cidadã: um debate sobre as práticas de educação em saúde.

5 (Re)construção de ações de educação em saúde a partir de círculos de cultura: experiência participativa com enfermeiras do PSF do Recife- PE.

6 Educação e promoção da saúde: uma retrospectiva histórica.

7 A Estratégia Saúde da Família como objeto BESEN, Candice Boppré et al. de educação em saúde.

8 Enfermeiro \& grupos em PSF: possibilidade para participação social.

9 Educação em saúde na escola: uma abordagem do currículo e da percepção de alunos de graduação em pedagogia.

10 Educação em saúde para portadores de doença mental: relato de experiência.
PEREIRA, Audrey Vidal; VIEIRA, Ana Luiza

Stiebler; FILHO, Antenor Amâncio.

SANTOS, Flavia Pedro dos Anjos et al.

BRITO, Juliana Santos Siebra.

VIDAL, Eglídia Carla Figueiredo et al.

PELICIONI, Maria Cecília Focesi; PELICIONI, Andréa Focesi.

SILVA, Maria da Anunciação et al.

LEONELLO, Valéria Marli; L'ABBATE, Solange.

RUIZ, Romeiro; LIMA, Alessandra Ribeiro MACHADO, Ana Lúcia.

\section{Periódicos}

Ano de

publicação Janeiro, v. 9, n. 1, p. 25- 41, mar./jun. 2011.

Physis. Revista de Saúde Coletiva, Rio de Janeiro, v. 21, n. 1, p. 267-281, 2011.

Monografia, Departamento de Saúde Coletiva, Centro de Pesquisas Aggeu Magalhães, Fundação Oswaldo Cruz.

Revista Gaúcha de Enfermagem, Porto Alegre, v. 29, n. 3, p. 475-480, 2008.

Tese de Doutorado, Universidade Federal do Ceará, Fortaleza.

OMundo da Saúde, São Paulo, v. 31, n. 3 , p. 320-328, jul./set. 2007.

Saúde e Sociedade, São Paulo, v. 16, n. 1, p. 57-68, jan./abr. 2007.

Cogitare Enfermagem, Curitiba, v. 11, n. 2, 2006 p. 143-149, maio/ago. 2006.

Interface: Comunicação, Saúde, Educação, Botucatu, v. 10, n. 19, p. 149-166, jan./jun. 2006.

Revista da Escola de Enfermagem da USP, São Paulo, v. 38, n. 2, p. 190-196, 2004. 


\section{Resultados}

\section{Caracterização das produções}

A Tabela 1 mostra a caracterização das produções incluídas na revisão integrativa da literatura.

\section{Tabela 1}

Caracterização das produções incluídas na revisão integrativa da literatura, de acordo com ano, natureza, modalidades, número de autores e características dos autores.

\begin{tabular}{|c|c|c|}
\hline Caracterização das produções $(n=10)$ & $\mathrm{n}$ & $\%$ \\
\hline \multicolumn{3}{|l|}{ Ano } \\
\hline 2004 & 1 & 10 \\
\hline 2006 & 2 & 20 \\
\hline 2007 & 3 & 30 \\
\hline 2008 & 1 & 10 \\
\hline 2010 & 1 & 10 \\
\hline 2011 & 2 & 20 \\
\hline \multicolumn{3}{|l|}{ Natureza } \\
\hline Artigo & 8 & 80 \\
\hline Tese & 1 & 10 \\
\hline Não especificado & 1 & 10 \\
\hline \multicolumn{3}{|l|}{ Modalidade } \\
\hline Revisão teórica & 5 & 50 \\
\hline Pesquisa de campo & 3 & 30 \\
\hline Outra modalidade & 2 & 20 \\
\hline \multicolumn{3}{|l|}{ Número de autores } \\
\hline Um & 2 & 20 \\
\hline Dois & 2 & 20 \\
\hline Três & 2 & 20 \\
\hline Mais de três & 4 & 40 \\
\hline \multicolumn{3}{|l|}{ Características dos autores } \\
\hline Docentes & 6 & 60 \\
\hline Assistentes & 3 & 30 \\
\hline Não especificado & 1 & 10 \\
\hline
\end{tabular}

Fonte: Os autores. 


\section{Evidências}

A análise temática das evidências permitiu identificar duas categorias: educação em saúde - historicidade e bases conceituais; e educação popular como geradora de cidadania.

\section{Educação em saúde: historicidade e bases conceituais}

O processo histórico da política de saúde é demarcado por características definidoras do poder hegemônico das pessoas pertencentes às classes sociais privilegiadas, ou é regido pelos interesses econômicos estabelecidos no Brasil.

A educação em saúde foi sendo delineada no decorrer desse processo histórico. Os primeiros conceitos sobre ES surgiram no final do século XIX e no início do século XX, quando o Brasil passava por um crescimento urbano, apresentando condições sanitárias ameaçadoras e o aparecimento de surtos epidêmicos. Nesse momento, conhecido como período higienista, a ES era realizada como processo formador de condutas saudáveis, por meio de discursos e práticas calcados em modelos de caráter coercitivo (Paulino, Fernandes e Siqueira, 2010).

No final do século XX, surge o movimento sanitário, que veio ao encontro das imposições feitas até o momento (Lima e Costa, 2005). Sua emersão permitiu a redução do 'poder de polícia' na saúde, o qual, naquela época, compreendia o confinamento de enfermos em desinfetórios e a vacinação compulsória da população, relegando a educação a um segundo plano (Pelicioni e Pelicioni, 2007).

O sanitarismo visava à educação sanitária, com o intuito de promover ações educativas que levassem a hábitos saudáveis por meio de orientações que tinham como objetivo a prevenção de doenças (Reis, 2006). Segundo Pelicioni e Pelicioni (2007), esse tipo de educação almejava apenas a transmissão de conhecimentos sobre higiene e cooperação em campanhas profiláticas.

Atualmente, ainda há uma herança do modelo cartesiano, o qual influencia o pensamento médico, desenvolvendo um enfoque reducionista e mecanicista que defende a ideia de que educar é para apenas prevenir. Diante desse paradigma biomédico, as práticas educativas em saúde tendem a reduzir-se a atividades preventivas, de cunho meramente informativo e coercitivo.

É válido salientar que, como a prática educativa em saúde refere-se às atividades de educação em saúde, o presente artigo defende os termos com esse mesmo sentido.

Sabe-se que a mudança desse paradigma vem sendo enfrentada historicamente, a exemplo dos movimentos sociais que passam a influenciar as práticas educativas hegemônicas. A intenção de substituir as práticas normativas, 
detentoras de pensamento curativista, para uma nova prática de educação em saúde, crítica e transformadora, direcionada à promoção da saúde, é a nova perspectiva das políticas públicas de saúde. Esse direcionamento aproxima os conceitos teórico-práticos tanto da educação como da saúde, gerando um saber híbrido que colabora na ampliação de conceitos e atitudes renovadores em ambos os setores.

Para Reis (2006), é no final do século XX que as ações educativas sofrem um deslocamento do paradigma das mudanças comportamentais por meio da informação para o das ações educativas participativas.

Com o início do movimento da reforma sanitária e sua expressiva representação de profissionais de saúde, população e participantes de movimentos populares, surge como produto o SUS, caracterizado pelos princípios de equidade, universalidade, integralidade e controle social. Sua formalização como sistema requereu uma revisão do modelo de atenção à saúde vigente, emergindo a necessidade de renovação nas propostas de atenção à saúde, com enfoque na promoção, entendida como um jeito de pensar e de fazer a saúde, na qual o cidadão tem autonomia e é instituinte de seu próprio modo de vida saudável, conhecedor do direito político, econômico e social à saúde.

A ES passa a ser uma estratégia para criação e fortalecimento do vínculo entre profissional e usuário, permitindo o autoconhecimento do indivíduo como ator social e o desenvolvimento de sua consciência crítica (Jesus et al., 2008).

Evidencia-se a necessidade de profissionais conscientes de sua importância social e política, sendo imprescindível visualizarem-se como educadores em saúde, mediadores na compreensão dos indivíduos como seres que têm o poder de modificar sua realidade.

As práticas educativas, segundo a visão de educação promotora de saúde, não são uma tarefa fácil. Segundo Alves (2005), o modelo tradicional, historicamente hegemônico, focalizando a doença e a intervenção curativa, fundamentado no referencial biologicista do processo saúde-doença e nas estratégias desta prática educativa em saúde, inclui informações verticalizadas que ditam comportamentos a serem adotados para a manutenção da saúde, daí a dificuldade em desenvolver tais ações. Freire (201 la) refere que os profissionais se baseiam em uma educação bancária, na qual se percebe uma metodologia de ensino verticalizada e não problematizadora. O educador possui visão alienante, o que o leva a exercer posições fixas, invariáveis e imutáveis, impedindo que a prática e o conhecimento sejam processos de busca permanente.

De acordo com Alves (2005), dentre as práticas de educação em saúde vivenciadas nas universidades, podem ser referidas a do modelo tradicional (educação sanitária) e a do modelo dialógico (educação crítica-reflexiva). 
Nesta, a educação baseia-se na valorização de experiências individuais e de grupos sociais, assim como no reconhecimento das diferentes realidades. Naquela, baseia-se na mudança de 'comportamentos individuais', seguindo uma pedagogia de ensino bancário (Souza et al., 2005). A relação entre os sujeitos se dá por meio de uma horizontalidade (Brasil, 2007b).

Para a efetivação de uma educação em saúde que contribua para o desenvolvimento de práticas críticas reflexivas, é necessário considerar a necessidade de definir campos de ação para a promoção da saúde, tais como construção de políticas públicas saudáveis; reorientação dos serviços de saúde; desenvolvimento de habilidades individuais; e reforço da ação comunitária, por meio da responsabilidade social. Essa opção deve estar fundamentada na análise da realidade que se faz mediante a identificação de problemas e das necessidades de saúde da população, para então estimular a reflexão crítica da realidade, sendo necessárias ações de educação em saúde voltadas para a melhoria dos determinantes da saúde (Alves e Aerts, 2011).

É necessário perceber que educar é mais do que apenas informar; é pensar a partir da reunião de histórias de vida do cidadão, em que haja direcionamento para a reflexão das necessidades, ou não, de mudanças na trajetória dessas vidas.

Em relação ao profissional/educador, Freire (2005) afirma que este deve ser capaz de testemunhar seu gosto pela vida, sua esperança num mundo melhor, atestar sua capacidade de luta, seu respeito às diferenças da realidade, e a maneira consistente com que assume sua presença no mundo. Para tanto, é importante notar que a ES deve objetivar a conscientização a respeito dos agravos à saúde, devendo haver uma comunicação bilateral que envolva educador e educando num processo dialógico, no qual ambos contribuam na construção do conhecimento, auxiliando na libertação das pessoas, para que estas possam ser sujeitos sociais capazes de realizar opções construtivas para si e para a sociedade de maneira geral.

Segundo Freire (2011a), a libertação é um parto doloroso; entretanto, só é viável na e pela superação da realidade concreta de opressão - a qual, mesmo que limite o homem, este é capaz de transformar (Freire, 201la). O caminho para um trabalho de libertação está no diálogo, o qual possibilita a conscientização com o objetivo de formar cidadãos da práxis progressista, transformadores da ordem social, econômica e política injusta (Freire, 2011 ). Compartilhando as ideias de Freire (2011a), pode-se dizer que o desenvolvimento da ES crítica-reflexiva é uma ferramenta que permitirá a libertação do indivíduo como ser ativo e responsável, norteando-se em um processo dialógico dos sujeitos nas ações e construções de saberes.

A educação em saúde possibilita a emancipação do sujeito, fortalecendo o vínculo entre democracia e educação. É necessário conhecer o outro e 
adentrar as práticas cotidianas para desenvolver habilidades que possibilitem trocas efetivas a fim de buscar uma inserção da pessoa na coletividade. Além disso, deve ser vista como direito social, constituindo-se historicamente um pré-requisito para a expansão dos demais direitos. A educação de sujeitos, voltada para a saúde, na perspectiva crítica, requer a compreensão de que a educação ocorre na forma de processo, em que aprender implica construir e não adquirir conhecimentos; significa desenvolver habilidades pessoais e sociais, e não adaptar ou reproduzir comportamentos (Lopes e Tocantins, 2012).

O objetivo da educação é o de oportunizar momentos de reflexões e ações capazes de possibilitar às pessoas um aprendizado consciente, sem a intenção de controlar suas vidas. A educação em saúde, vista neste contexto, pode ser compreendida no sentido de propiciar encontros entre profissionais e usuários do serviço de saúde. Essa relação face a face representa um modo de fomentar o diálogo e a troca de experiências.

As práticas de saúde decorrem de experiências contínuas de ensino-aprendizagem e acabam influenciando as decisões a serem tomadas ao longo da existência dos indivíduos, podendo contribuir para diminuir, manter ou elevar o seu nível de saúde. Dessa maneira, a educação em saúde pode ser definida como qualquer combinação de experiência de aprendizagem, delineada para facilitar ações voluntárias conducentes à saúde.

A priori, a educação em saúde é uma construção em movimento; por esta razão torna-se fundamental trabalhar situações conforme a realidade das pessoas, valorizando aspectos culturais, as relações de gênero e os diferentes níveis socioeconômicos e políticos.

Os profissionais de saúde devem utilizar a educação em saúde como instrumento de trabalho à medida que o setor perpassa todos os aspectos do viver humano e requer, para a transformação dos sujeitos, uma profunda interação entre o profissional desta área e a população, visando permeabilizar as condutas que gerem saberes (Santos et al., 2011).

\section{Educação popular como geradora de cidadania}

A educação popular em saúde foi sendo construída na década de 1970 (Vasconcelos, 2006). A aproximação com o mundo popular visou ao desenvolvimento de uma metodologia que não se adequasse à forma autoritária, como a das elites. O saber produzido pelas massas populares era capaz de fazê-las viver com dificuldades, produzindo, apesar disso, momentos prazerosos e de alegria. A junção do conhecimento científico e técnico com o saber e iniciativas populares era capaz de provocar movimentos que saíssem do lugar-comum da passividade e da aceitação para a luta por mudanças (Brito, 2010). 
Ante os movimentos populares, a educação popular em saúde (EPS) prioriza projetos pedagógicos que permitam diversidade social, intercomunicação de diferentes atores sociais e o compromisso com classes populares, valorizando as iniciativas dos educandos e o diálogo entre o saber popular e o científico (Vasconcelos, 2006). Portanto, tem como compromisso maior a emancipação e a cidadania da população brasileira (Brasil, 2009). Sua prática implica sempre atos criativos do educador, para facilitar a problematização do objeto de conhecimento a ser descoberto e aprendido pelos educandos (Hurtado, 2006).

Na educação popular, um dos elementos centrais do seu método é tomar como ponto de referência o conhecimento e o saber prévio dos educandos, rumo à construção compartilhada de um processo educativo que valorize as singularidades dos sujeitos sociais (Vasconcelos, 2008; Alvim e Ferreira, 2007).

A EPS pode ser entendida nos marcos da educação libertadora de Paulo Freire (Moreira et al., 2007). Segundo Freire (2011a), a liberdade é uma conquista e não uma doação; sendo assim, exige uma permanente busca. Este autor ainda enfatiza que o caminho para essa libertação é a prática de uma pedagogia humanizadora, na qual se estabelece uma relação dialógica permanente (Freire, 2011a).

Dessa maneira, a EPS vem inovar na metodologia vertical na relação entre o educador e o educando. Segundo Vasconcelos (2007):

A Educação Popular não visa criar sujeitos subalternos educados: sujeitos limpos, polidos, alfabetizados, bebendo água fervida, comendo farinha de soja e utilizando fossas sépticas. Visa participar do esforço que já faz (sic) hoje as categorias de sujeitos submetidos para que a organização do trabalho político, passo a passo, abra caminho para a conquista de sua liberdade e de seus direitos (Vasconcelos, 2007, p. 20-21).

Atualmente, a EPS tem evoluído como alternativa de ES para o desenvolvimento de uma assistência integral em que haja uma relação coparticipante entre o educando e o educador. Entretanto, verifica-se que alguns profissionais, além de exporem resistência, influenciados pelo modelo cartesiano, apresentam dificuldades em reconhecer o momento de vacinação, consulta e coleta de exames preventivos como um espaço para agir de forma educativa. Demonstram, não raramente, um forte distanciamento das práticas educativas.

As mudanças vinculadas ao desenvolvimento de uma pedagogia tradicional devem ser revistas pelo profissional para que ele não se restrinja à aplicação de técnica em seu trabalho, mas também realize uma ação pedagógica que promova a articulação entre teoria e prática, permitindo o envolvimento do cidadão no processo de construção do cuidado à sua saúde. 
A EPS deve problematizar o que determina a situação de adoecimento, sofrimento e cuidado a partir de concepções, saberes e representações sociais da população (Bonetti, Pedrosa e Siqueira, 2011).

É importante lembrar que a ES sofreu significativas mudanças no decorrer do tempo e, atualmente, representa um elemento de transformação social que deve permitir a valorização da vida e o estímulo à formação do cidadão. Entretanto, a ES, apesar de ser complexa, é viável e possível, desde que os profissionais de saúde a promovam com a finalidade de mobilizar cidadãos em direção a uma sociedade mais fraterna e comprometida na promoção da vida, e que esses cidadãos sejam receptivos e coparticipantes desse processo intersetorial, envolvendo a educação e a saúde (Santos et al., 2011).

\section{Considerações finais}

A pesquisa trouxe fundamentação teórica de diversos autores a respeito das concepções sobre educação em saúde e cidadania. Possibilitou-nos identificar alguns aspectos que vêm marcando a temática estudada.

Observa-se que a educação em saúde, com a reforma sanitária e a formalização do SUS, passou a ser inserida como modelo de atenção à saúde, enfocando a promoção à saúde e sendo considerada estratégia essencial no processo de conscientização individual e coletiva da sociedade.

Tal modelo surge para substituir a educação com foco na culpabilização da população, contemplando atividades predominantemente curativas e reabilitadoras. Apesar de perceber que essa educação tradicional ainda seja realizada pelos profissionais, a introdução de uma prática crítica e transformadora está sendo estratégia de escolha na busca de um indivíduo crítico-reflexivo. Em virtude disso, procurou-se, nesta pesquisa, evidenciar, por meio da revisão integrativa da literatura, a temática educação em saúde com foco em sua historicidade e bases conceituais, assim como a educação popular nos serviços de saúde, como geradora de cidadania.

Educar em saúde não é se restringir apenas a repassar informações; é também sensibilizar a população a respeito dos agravos à saúde, levando-se em consideração o processo dialógico a orientar as práticas educativas que envolvem os sujeitos nas ações e na construção/reconstrução.

A educação promotora em saúde tem sido destacada como emancipadora do sujeito, permitindo que ele transforme sua realidade e estimule experiências para o desenvolvimento de melhores condições de vida e promoção da saúde. As práticas educativas em saúde facilitam a troca de conhecimento e experiências entre os membros da comunidade e profissionais, com isso fornecendo liberdade a momentos de debates reflexivos que possibilitam às pessoas um aprendizado significativo. 
Se, atualmente, tenta-se implementar, como modelo norteador da educação em saúde, o enfoque dialógico, então a educação popular é uma importante metodologia dialógica, pois rompe com uma visão tradicionalista e normatizadora, incluída nas atividades que envolvem não apenas a aplicação técnica do profissional, mas também ação pedagógica, em uma comunicação bilateral, como geradora de cidadania.

Com esta revisão teórica, buscou-se contribuir para a reflexão sobre o delineamento da educação em saúde. Sabe-se que essa ferramenta ainda é uma prática arraigada em concepções tradicionais, as quais levam tempo para ser modificadas, necessitando de uma mudança processual. Entretanto, vários autores enfocam a importância da discussão sobre tal temática, relacionada a aspectos importantes como a promoção da saúde e a qualidade de vida.

\section{Colaboradores}

Viviane Ferraz Ferreira foi a responsável pela coleta e análise dos dados, método, resultado e considerações finais; Genylton Odilon Rêgo da Rocha e Márcia Maria Bragança Lopes orientaram o trabalho; Milena Silva dos Santos responsabilizou-se pela coleta e análise de dados, introdução e resultado; e Shirley Aviz de Miranda, pela coleta e análise de dados, resumo, abstract, método e resultado. 
Resumen Este artículo presenta los resultados de una revisión integradora de la literatura sobre educación en salud y ciudadanía, que trató de conocer y analizar los diferentes aportes científicos disponibles. La educación en salud refleja una estrategia que anhela un ciudadano coautor del proceso de construcción del cuidado de la salud. Para recopilar los datos se utilizó la base de datos LILACS (Literatura Latinoamericana y del Caribe en Ciencias de la Salud), en el período de 2000 a 2011, con un total de 79 producciones. Después de aplicar los criterios de inclusión y exclusión, la muestra final estuvo compuesta por diez publicaciones. La investigación mostró la prevalencia de estudios con naturaleza de artículo, con presencia de más de tres autores, predominancia de docentes y producción tipo revisión teórica. Las categorías que surgieron del estudio fueron: educación en salud, antecedentes históricos y bases conceptuales, y educación popular como generadora de ciudadanía. Las evidencias mostraron el proceso histórico de las políticas de salud y la aparición de los movimientos sociales orientados a las necesidades de la población. También destacaron que la educación permanente en salud fomenta la construcción de saber, a través de la combinación de conocimientos científicos y conocimientos populares. Se manifestaron en la literatura contribuciones relevantes sobre la educación en salud, por ser una práctica emancipadora del individuo, actuando como espacio generador de ciudadanía.

Palabras clave educación en salud; ciudadanía; educación.

\section{Notas}

1 Universidade Federal do Pará, Belém, Pará, Brasil.

Mestranda do Programa de Pós-Graduação em Enfermagem, Universidade Federal do Pará. <viviane.ferraz@yahoo.com.br>

Correspondência: Conjunto Cidade Nova 5 WE 58, 942, Coqueiro, CEP 67133-410, Ananindeua, Pará, Brasil.

2 Universidade Federal do Pará, Belém, Pará, Brasil

Doutor em Geografia pela Universidade de São Paulo e pós-doutor pelo Institut National de Recherche Pédagogique, França. <genylton@gmail.com>

3 Universidade Federal do Pará, Belém, Pará, Brasil.

Doutora em Filosofia da Enfermagem pela Universidade Federal de Santa Catarina.

$<$ mmbl@ufpa.br $>$

4 Universidade Federal do Pará, Belém, Pará, Brasil

Mestranda em Enfermagem pela Universidade Federal do Pará.

<princessmilinha@hotmail.com>

5 Universidade Federal do Pará, Belém, Pará, Brasil.

Mestranda em Enfermagem pela Universidade Federal do Pará.

<shirleyaviz@hotmail.com> 


\section{Referências}

ALVES, Gehysa G.; AERTS, Denise. As práticas educativas em saúde e a Estratégia Saúde da Família. Ciência \& Saúde Coletiva, Rio de Janeiro, v. 16, n. 1, p. 319-325, 2011.

ALVES, Vânia S. Um modelo de educação em saúde para o Programa Saúde da Família: pela integralidade da atenção e reorientação do modelo assistencial. Interface: Comunicação, Saúde, Educação, Botucatu, v. 9, n. 16, p. 39-52, set. 2004/fev. 2005.

ALVIM, Neide A. T.; FERREIRA, Márcia de A. Perspectiva problematizadora da educação popular em saúde e a enfermagem. Texto \& Contexto: Enfermagem, Florianópolis, v. 16, n. 2, p. 315-319, 2007.

BONETTI, Osvaldo P.; PEDROSA, José I. dos S.; SIQUEIRA, Theresa Cristina de A. Educação popular em saúde como política do Sistema Único de Saúde. Revista de APS, Juiz de Fora, v. 14, n. 4, p. 397-407, out./dez. 2011. Disponível em: <www.aps.ufjf.br/index.php/aps/article/ viewFile/1607/551>. Acesso em: 20 maio 2013.

BRASIL. Ministério da Saúde. Secretaria de Gestão Estratégica e Participativa. Departamento de Apoio à Gestão Participativa. Caderno de Educação Popular e Saúde. Brasília: Ministério da Saúde, 2007a.

Ministério da Saúde. Fundação Nacional de Saúde. Educação em saúde: diretrizes. Brasília: Funasa, 2007b. Disponível em: $<$ www.funasa.gov.br/site/wp-content/files_ mf/dir_ed_sau.pdf>. Acesso em: 7 set. 2012.

Ministério da Saúde. Comitê Nacional de Educação Popular em Saúde (CNEPS). Portaria n. 1.256/GM, de 17 de junho de 2009. Institui o Comitê Nacional de Educação Popular em Saúde (CNEPS). Disponível em: $<$ http://portal.saude.gov.br/portal/arquivos/ pdf/portaria_1256_GM_2009.pdf $>$. Acesso em: 20 maio 2013.

BRITO, Juliana S. S. Educação popular em saúde com a comunidade indigena Xukuru do
Ororubá-PE. 2010. 53 f. Monografia (Programa de Residência Multiprofissional em Saúde Coletiva) - Fundação Oswaldo Cruz, Centro de Pesquisas Aggeu Magalhães, Departamento de Saúde Coletiva, Recife, 2010.

SÃO PAULO (Estado). Conselho Regional de Enfermagem. Guia de cidadania: novos tempos: novos desafios. Semana da Enfermagem, 2009. Disponível em: <http://inter.coren-sp. gov.br/sites/default/files/guia_cidadania. pdf $>$. Acesso em: 20 maio 2013.

FERNANDES, Maria C. P.; Backes, Vânia M. S. Educação em saúde: perspectivas de uma equipe da Estratégia Saúde da Família sob a óptica de Paulo Freire. Revista Brasileira de Enfermagem, Brasília, v. 63, n. 4, p. 567-573, jul./ago. 2010.

FREIRE, Paulo. Educação como prática de liberdade. 28. ed. São Paulo: Paz e Terra, 2005.

Pedagogia do oprimido. 50. ed. rev. atual. São Paulo: Paz e Terra, 2011 a.

Pedagogia da autonomia: saberes necessários à prática educativa. São Paulo: Paz e Terra, 2011b.

HURTADO, Carlos N. Contribuições para o debate latino-americano sobre a vigência e a projeção da educação popular. In: PONTUAL, Pedro; IRELAND, Timothy (Org.). Educação popular na América Latina: diálogos e perspectivas. Brasília: Ministério da Educação; Unesco, 2006. p. 147-156. (Coleção educação para todos).

JESUS, Maria C. P. et al. O discurso do enfermeiro sobre a prática educativa no Programa Saúde da Família em Juiz de Fora, Minas Gerais, Brasil. Revista de APS, Juiz de Fora, v. 11, n. 1, p. 54-61, jan./mar. 2008.

LIMA, Keite A.; COSTA, Fátima N. A. Educação em saúde e pesquisa qualitativa: relações possíveis. Alimentos e Nutrição, Araraquara, v. 16, n. 1, p. 33-38, jan./mar. 2005. 
LOPES, Márcia M. B. Educação em enfermagem na UFPA e a práxis da enfermeira na atenção básica de saúde. 2009. 270f. Tese (Doutorado em Enfermagem) - Universidade Federal de Santa Catarina, Florianópolis, 2009.

LOPES, Rosane; TOCANTINS, Florence R. Promoção da saúde e a educação crítica. Interface: Comunicação, Saúde, Educação, Botucatu, v. 16, n. 40, p. 235-246, jan./mar. 2012.

MOREIRA, Janine et al. Educação popular em saúde: a educação libertadora mediando a promoção da saúde e o empoderamento. Contrapontos, Itajaí, v. 7, n. 3, p. 507-521, set./dez. 2007. Disponível em: <www6. univali.br/seer/index.php/rc/article/view/ 920/775 > . Acesso em: 18 maio 2013.

PAULINO, Luciana F.; FERNANDES, Wânia R.; SIQUEIRA, Vera H. F. Educação, saúde e velhice: articulações prevalentes em periódicos. Rempec: Ensino, Saúde e Ambiente, Rio de Janeiro, v. 3, n. 2, p. 87-97, ago. 2010.

PELICIONI, Maria C. F.; PELICIONI, Andréa F. Educação e promoção da saúde: uma retrospectiva histórica. O Mundo da Saúde, São Paulo, v. 31, n. 3, p. 320-328, jul./set. 2007.

POMPEO, Daniele A.; ROSSI, Lídia A.; GALVÃO, Cristina M. Revisão integrativa: etapa inicial do processo de validação de diagnóstico de enfermagem. Acta Paulista de Enfermagem, São Paulo, v. 22, n. 4, p. 434438, 2009. Disponível em: <http://www. scielo.br/pdf/ape/v22n4/al4v22n4.pdf $>$. Acesso em: 12 maio 2011.
REIS, Dener C. Educação em saúde: aspectos históricos e conceituais. In: GAZZINELLI, Maria F.; REIS, Dener C.; MARQUES, Rita C. (Org.). Educação em saúde: teoria, método e imaginação. Belo Horizonte: Editora UFMG, 2006. p. 19-24.

SANTOS, Flávia P. A. et al. Estratégias de enfrentamento dos dilemas bioéticos gerados pela violência na escola. Revista de Saúde Coletiva, Rio de Janeiro, v. 21, n. 1, p. 267-281, 2011.

SOUZA, Aline C. et al. A educação em saúde com grupos na comunidade: uma estratégia facilitadora da promoção da saúde. Revista Gaúcha de Enfermagem, Porto Alegre, v. 26, n. 2, p. 147-153, 2005.

SOUZA, Marcela T.; SILVA, Michelly D.; CARVALHO, Rachel . Revisão integrativa: o que é e como fazer. Einstein, São Paulo, v. 8, p. 102-106, 2010. Disponível em: $<$ http://astresmetodologias.com/material/ O_que_e_RIL.pdf >. Acesso em: 19 out. 2011.

VASCONCELOS, Eymard M. Educação popular e atenção à saúde da família. 3. ed. São Paulo: Hucitec, 2006.

Educação popular: um instrumento de gestão participativa dos serviços de saúde. In: BRASIL. Secretaria de Gestão Estratégica e Participativa. Caderno de educação popular e saúde. Brasília: Ministério da Saúde, 2007. p. 18-29.

Espiritualidade, educação popular e luta política pela saúde. Revista de APS, Juiz de Fora, v. 11, n. 3, p. 314-325, 2008.

Recebido em 20/03/2012

Aprovado em 23/07/2013 